\title{
Reducing Substance Use and HIV Health Disparities among Hispanic Youth in the USA: The Familias Unidas Program of Research*
}

\section{Reduciendo las Desigualdades en Salud por Consumo de Drogas y VIH en los Jóvenes Hispanos de EEUU: El Programa de Investigación Familias Unidas}

\author{
Guillermo Prado and Hilda Pantin \\ University of Miami, USA
}

\begin{abstract}
Preventing/reducing substance use and HIV among Hispanic youth is essential to eliminating the health disparities that exist between Hispanics and other segments of the population. The objective of this article is to describe a program of research involving Familias Unidas, a Hispanic-specific, parent-centered intervention, aimed at reducing substance use and HIV health disparities among Hispanic youth. This article will focus on the theoretical foundation of the intervention, the empirical research supporting the theoretical model, the intervention model itself, the findings of the program of research, and the translation of this intervention into community practice.

Keywords: drugs, family, health disparities, hispanic, HIV, smoking.
\end{abstract}

Resumen. Prevenir/reducir el uso de drogas y la incidencia de VIH entre los jóvenes hispanos es imprescindible para eliminar las desigualdades existentes en materia de salud entre los hispanos y otros sectores de la población. El objetivo de este artículo es describir el programa de investigación Familias Unidas (un programa de intervención diseñado específicamente para hispanos y que se centra en el papel de los padres). El programa pretende reducir el consumo de drogas y minimizar las disparidades relativas al VIH entre los jóvenes hispanos. El artículo se centra en las bases teóricas de la intervención, en la investigación empírica que respalda este modelo teórico, en el modelo mismo, en los resultados obtenidos por el programa de investigación, y en su puesta en práctica en la comunidad.

Palabras clave: desigualdad de salud, drogas, familia, fumar, hispano, VIH.

Substance use (including cigarette, alcohol, and illicit drug use) and HIV represent major public health problems facing America's youth (Centers for Disease Control and Prevention, 2010; Johnston, O'Malley, Bachman, \& Schulenberg, 2009). Early substance use and unsafe sexual behavior, along with the outcomes with which these behaviors are associated, such as substance abuse and dependence (Gil, Wagner, \& Tubman, 2004) and HIV (Centers for Disease Control and Prevention, 2010; Prado, Schwartz, Pattatucci-Aragon et al., 2006), are not evenly distributed across ethnic groups. In fact, both substance use and HIV contribute largely to the health disparities that exist between Hispanics and other segments of the population. Thus, preventing/reducing substance use and HIV among Hispanic youth is essential to eliminating the health disparities that exist between Hispanics and other segments of the population. Despite these substance use and HIV

Correspondence: Guillermo Prado. 1425 N.W., $10^{\text {th }}$ Ave., $3^{\text {rd }}$ floor, Miami, FL 33136, USA. E-mail: gprado@med.miami.edu; Hilda Pantin. 1425 N.W., $10^{\text {th }}$ Ave., $3^{\text {rd }}$ floor, Miami, FL 33136, USA. E-mail: hpantin@med.miami.edu

* Versión en castellano disponible en [Spanish version available at]: www.psychosocial-intervention.org health disparities among this population, there is a dearth of evidence based interventions for preventing substance use and HIV risk behaviors among Hispanic youth. To our knowledge, Familias Unidas is the only intervention program with demonstrated efficacy in preventing both substance use and unprotected sexual behavior among this population. Familias Unidas is also the only published intervention for Hispanic youth that has been evaluated in more than one randomized clinical trial (O'Connell, Boat, \& Warner, 2009). The objective of this article will be to describe a program of research involving Familias Unidas, a Hispanic-specific, parent-centered intervention, found to be efficacious in reducing health disparities in substance use and HIV risk behaviors among Hispanic youth. This article will focus on the theoretical foundation of the intervention, the empirical research supporting the theoretical model, the intervention model itself, the findings of the program of research and the translation of this intervention into community practice. Before we present the intervention, it is important to understand the epidemiology of substance use and HIV among Hispanic youth. The next section describes the prevalence of substance use and HIV risk behaviors among Hispanic youth. 


\section{Prevalence of Substance Use and HIV Risk Behaviors among Hispanic Youth}

Adolescents comprise an important at-risk population for substance use (including illicit drug use, cigarette use and alcohol use). Although substance use represents a major public health problem facing all of America's youth, Hispanic youth report disproportionate use of illicit drug use, alcohol use and cigarette use. Results from a recent school-based Monitoring the Future survey (Johnston et al., 2009) indicate that Hispanic $8^{\text {th }}$ grade adolescents report higher lifetime and current use across all drug categories (with the exception of amphetamines) than both non-Hispanic Whites and African Americans. For example, 23.9\% of Hispanic $8^{\text {th }}$ graders report having ever used an illicit drug compared to $19.4 \%$ of African Americans and $17.5 \%$ of non-Hispanic Whites (Johnston et al., 2009).

With respect to cigarette use, Hispanic $8^{\text {th }}$ and $10^{\text {th }}$ graders also report higher rates of cigarette use than their non-Hispanic White and African American counterparts. For example, $24.1 \%$ of Hispanic $8^{\text {th }}$ graders report having smoked cigarettes in their lifetime compared to $20.8 \%$ of African American and $20.4 \%$ of non-Hispanic White $8^{\text {th }}$ graders (Johnston et al., 2009). Similarly, $36.1 \%$ of Hispanic $10^{\text {th }}$ graders report having smoke cigarettes in their lifetime compared to $27.9 \%$ of African Americans and $33.7 \%$ of nonHispanic Whites (Johnston et al., 2009). Finally, Hispanic $8^{\text {th }}$ and $10^{\text {th }}$ graders also report higher rates of alcohol use than their non-Hispanic White and African American counterparts. For example, $47.1 \%$ of Hispanic $8^{\text {th }}$ graders report having drank alcohol in their lifetime compared to $37.1 \%$ of African American and $36.8 \%$ of non-Hispanic White $8^{\text {th }}$ graders (Johnston et al., 2008).

Although Hispanics $10^{\text {th }}$ graders report higher rates of illicit drug use, alcohol use and cigarette use than both non-Hispanic Whites and African Americans, by the $12^{\text {th }}$ grade Hispanic youth report lower rates of use than non-Hispanics Whites (although still higher than African Americans).

Several explanations have been posited for this change in ranking between the $10^{\text {th }}$ and $12^{\text {th }}$ grades. One possible explanation is that Hispanic adolescents drop out of school at considerably higher rates than both African Americans and non-Hispanic Whites. Thus, compared to both non-Hispanic Whites and African Americans, a larger percentage of the drugprone segment of Hispanics may drop out before twelfth grade (Greene \& Forster, 2003). However, evidence from non-school-based surveys may contradict the high school dropout hypothesis. Specifically, the population-based National Household Survey on Drug Use and Health (Substance Abuse and Mental Health Service Administration, 2005) has found that during late adolescence and emerging adulthood, nonHispanic whites have the highest rates of drug use, fol- lowed by Hispanics. Another alternative explanation could be that Hispanics tend to initiate drug use earlier and that non-Hispanic whites initate later and surpass Hispanic use rates by $12^{\text {th }}$ grade.

In addition to risks for illicit drug use, alcohol use and cigarette use, adolescents comprise an important at-risk population for engaging in unsafe sexual behaviors. Results from The CDC's Youth Risk Behavior Surveillance Survey (Centers for Disease Control and Prevention, 2010), indicate that $46 \%$ of high school students reported having had sexual intercourse and $13.8 \%$ reported four or more lifetime sexual partners. Moreover, of those adolescents who reported having sex within three months prior to completing the survey, only $61.1 \%$ reported using a condom at last sexual intercourse. Illicit drug use is also a major risk factor for engagement in unsafe sexual behavior and therefore for HIV infection (Guo, Chungh, Hill et al., 2002; Prado et al., 2006). According to the CDC's Youth Risk Behavior Surveillance Survey of those adolescents who reported having sex within three months prior to completing the survey, $21.6 \%$ reported drinking alcohol or using illicit drugs before last sexual intercourse. It may not be surprising then that 13 to 19 year old youth comprise the fastest growing group of new HIV cases (Eaton, Kann, Kinchen et al., 2006).

These rates are even more alarming among Hispanic adolescents. For example, the proportion of Hispanic adolescents reporting condom use at last sexual intercourse is lower (54.9\%) than that of African American youth $(62.4 \%)$. Although the most recent report of the Youth Risk Behavior Surveillance Survey shows that the proportion of non-Hispanic White (63.3\%) reporting condom use is higher than that of Hispanics, Hispanics have report lower condom use than nonHispanic Whites since the inception of this survey in 1991 (Centers for Disease Control and Prevention, 2007). The fact that Hispanics have reported lower rates of condom use is disconcerting because unprotected sex at last sexual intercourse is a major source of risk for HIV infection (Eaton et al., 2006). It is important to note, however, that Hispanics are not at most risk on all sexual risk indicators. For example, a fewer proportion $(14.2 \%)$ of Hispanic youth report having had sexual intercourse with four or more persons in their life compared to African-Americans (28.6\%).

In summary, although the national statistics are alarming for all youth, what may be even more disconcerting is that Hispanic youth, the largest and fastest growing minority group in the United States (Ramirez $\&$ de la Cruz, 2003), appear to be at heightened risk for engaging in drug use, cigarette use, alcohol use and unsafe sexual behavior. Given (a) the disproportionate rates of these behaviors, as well as the disproportionate prevalence rates of HIV among Hispanic adolescents (i.e., Hispanic youth account for $18 \%$ of all new HIV cases; CDC, 2005), (b) the youthful nature of the U.S. Hispanic population (approximately one-third of all 
Hispanics are under the age of 18; (Marotta \& Garcia, 2003)) and (c) the Hispanic population's rate of expansion (Hispanics accounted for almost half (1.4 million) of the national population growth of 2.9 million between July 1, 2005 and July 1, 2006; U.S. Census Bureau, 2008), developing, evaluating and disseminating evidence-based interventions for Hispanics is an urgent public health issue and essential to reducing the substance use and HIV health disparities that exist between Hispanic youth and other segments of the population.

The remaining majority of this article focuses on a program of research entitled "Familias Unidas" [United Families]. The Familias Unidas program of research is designed to reduce the substance use and HIV health disparities in Hispanic youth. By reducing illicit drug use, cigarette use, alcohol use and unsafe sexual behavior among Hispanic youth, we can improve the health of this population (Mokdad, Marks, Stroup, \& Gerberding, 2004). In the next sections, we describe, the theoretical foundation of the Familias Unidas intervention, the empirical research supporting the theoretical model, the intervention model itself, the findings of the program of research and the translation of this intervention into community practice.

\section{Etiology of Substance Use and HIV risk Behaviors: Risk and Protective Processes}

To begin to understand the theoretical underpinnings of Familias Unidas, one must first understand the etiology - the risk and protective processes - associated with substance use and HIV risk behaviors among Hispanic youth. In the adolescent health literature, risk for the development of substance use and unsafe sexual behavior has been conceptualized as a multidimensional process with "multiple pathways" to these developmental outcomes (Bry, McKeon, \& Pandina, 1982). Research has documented that difficulties in several different domains of functioning interact to increase the likelihood of substance use and unsafe sexual behavior (Hovell, Sipan, Blumberg et al., 1994; Hawkins, Catalano, \& Miller, 1992). Although individual risks are typically studied as independent or additive elements in a risk model, they may be more accurately expressed as elements of an integrated developmental risk process (Szapocznik \& Coatsworth, 1999).

Due to the presence of risks for substance use and other HIV risk behaviors (e.g., unprotected sexual behavior) at multiple levels of the social environment and to the potential for these risks to compound one another's effects, there is a need for multidimensional understandings of risk and protection vis-à-vis adolescent substance use (Dishion, Capaldi, \& Yoerger, 1999) and unsafe sexual behavior (Kotchick, Shaffer, Forehand, \& Miller, 2001). Social ecological models can help explain the multiple effects and interrelated- ness of substance use and HIV risk behaviors in adolescents. Models based on ecodevelopmental theory (Prado et al., 2010; Szapocznik \& Coatsworth, 1999) are examples of such social-ecological models. The Familias Unidas intervention is based on ecodevelopmental theory (Pantin et al, 2004; Prado et al., 2010).

Ecodevelopmental theory (Pantin, Coatsworth, Feaster et al., 2004; Szapocznik \& Coatsworth, 1999) incorporates three primary, integrated elements: (a) social ecological theory, (b) developmental theory and (c) an emphasis on social interactions. The first element of ecodevelopmental theory is drawn from Bronfenbrenner's work on the social ecology of human development (Bronfenbrenner, 1979, 1986). Bronfenbrenner has organized the multiple influences on adolescent development according to their proximity to the adolescent, presented here from furthest to closest: macrosystems (the broad social and philosophical ideals that define a particular culture, e.g. cultural values); exosystems (contexts in which the adolescent does not participate directly but that impact the functioning of important members of the adolescent's life, such as parents' support systems); mesosystems (contexts which are comprised of the interactions between important members of the different contexts in which the adolescent participates directly, e.g. parental monitoring of peers) and microsystems (contexts in which the adolescent participates directly, such as the family).

The second element of ecodevelopmental theory is a developmental perspective that emphasizes the changing nature of youth across time as a function not only of the adolescent's current social context but also of changing conditions in the social context throughout the child's life. Hence, a developmental perspective is applied to the youth and her/his social context, where both person and context are viewed as evolving and changing across the lifespan. For example, adolescent drug use, a predictor of unsafe sexual behavior (Bailey, Pollock, Martin, \& Lynch, 1999; Boyer, Tschann, \& Shafer, 1999), is influenced not only by the youth's current social context, as manifested by parental monitoring of adolescent's peers (Bogenschneider, Wu, Raffaelli, \& Tsay, 1998) during adolescence, but also by previous levels of parental investment and family communication (Barnes, Farrell, \& Banerjee, 1994).

The third element of ecodevelopmental theory is social interactions. We hypothesize that risk and protection are expressed in the patterns of relationships and direct transactions between individuals within and across the different contextual levels (Garbarino \& Abramowitz, 1992; Szapocznik \& Coatsworth, 1999). For example, the amount of social support experienced by parents is directly predictive of the harshness or supportiveness in their parenting (Swick \& Broadway, 1997), which in turn may affect the likelihood of adolescent drug use and unsafe sexual behavior (Miller, Levin, Whitaker, \& Xu, 1998; Perkins \& Luster, 1999; Whitbeck, Conger, \& Kao, 1993). Thus, ecodevelop- 
mental theory (Pantin et al., 2004) suggests that macrosystemic phenomena, such as the mismatch between a family's culture of origin and that of the host country, produce a "trickle-down" effect by contributing to exosystemic problems such as parental isolation, which in turn may cut parents off from their adolescents' peer networks (i.e., mesosystemic problems) (Pantin et al., 2003; Pantin, Schwartz, Sullivan et al., 2004). For example, the clinical literature suggests that when immigrant parents are unfamiliar with the culture of their new homeland, they tend to remain isolated and not to reach out for social support (Leon \& Dziegielewski, 2000). Lack of social support, in turn, may inhibit supportive and involved parenting (Simons, Lorenz, Conger, \& Wu, 1992). Lack of parental involvement in the adolescent's life (microsystemic problem) and peer worlds (mesosystemic problem) then increases the likelihood of problem behaviors, including drug use (Pabon, 1998) and unsafe sexual behavior (Boyer et al., 1999; Luster \& Small, 1994). These ecodevelopmental effects may be particularly important in the lives of Hispanic immigrant adolescents and families, given that for Hispanics, experiences related to immigration and acculturation are predictive of drug use (Martinez, 2006) and unsafe sexual behavior (Ford \& Norris, 1993). The Familias Unidas intervention addresses these ecodevelopmental processes that are specific to Hispanic immigrant families (Figure 1).

\section{Familias Unidas Intervention Targets}

Ecodevelopmental principles have been applied successfully to adolescent substance use and HIV preventive interventions. A considerable body of research has documented that preventive interventions targeting the family context have been successful in reducing

Figure 1. Ecodevelopmental Processes addressed by Familias Unidas

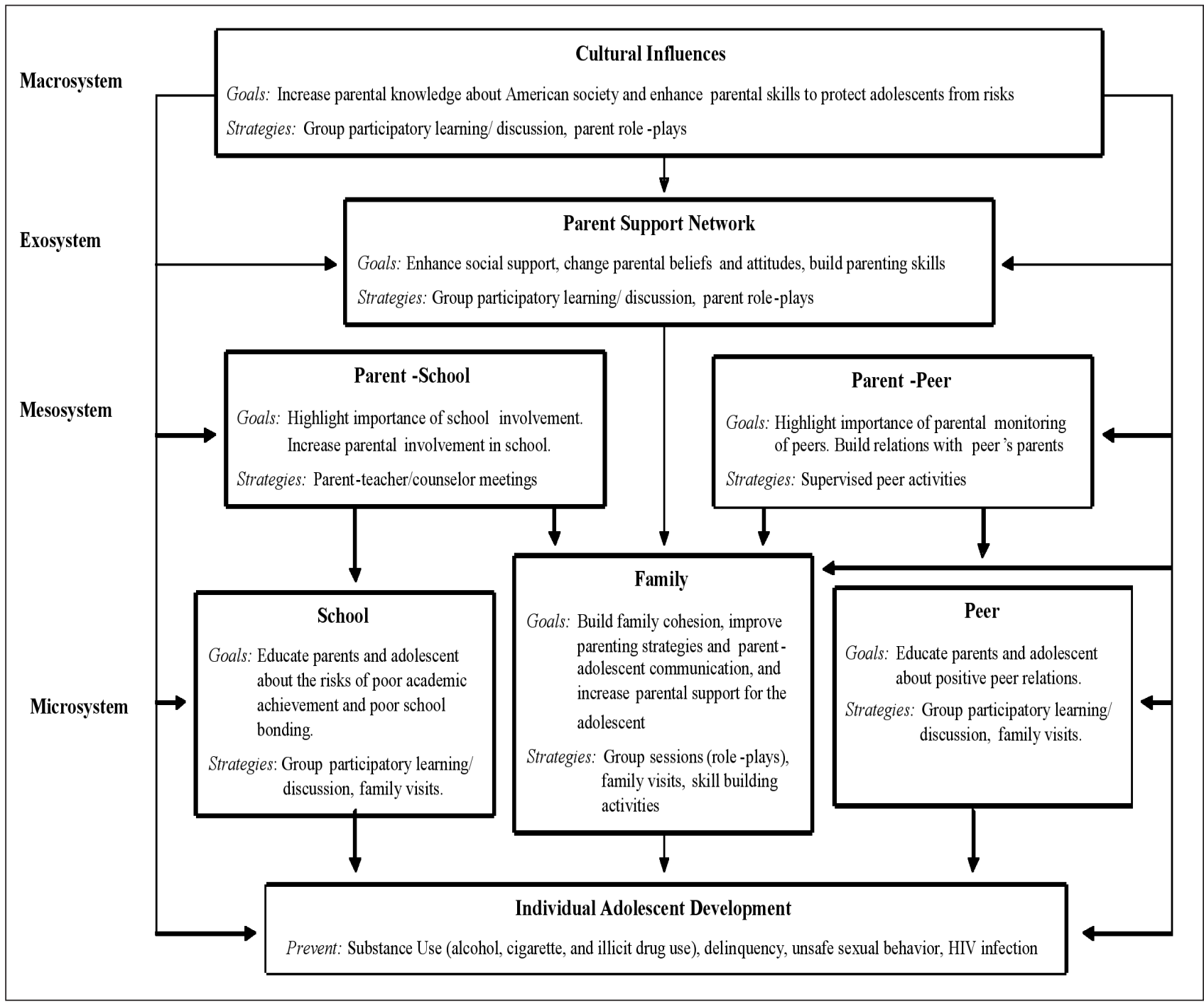


risk for adolescent substance use and unprotected sexual behavior (Dishion et al., 1999; Ialongo, Werthamer, Kellam, et al., 1999; Kumpfer, Molgaard, \& Spoth, 1996; Pentz, 1995; Pentz, Dwyer, MacKinnon et al., 1989; Prado, Pantin, Briones et al., 2007; Szapocznik, Scopetta, \& King, 1978; Tobler, Roona, Ochshorn et al., 2000). Preventive interventions targeting community and school contexts (Dishion, Kavanagh, Schneiger et al., 2002; Hawkins et al., 1992; Kulis, Marsiglia, Elek et al., 2005; Pentz, 1995; Pentz et al., 1989; Storr, Ialongo, Kellam, \& Anthony, 2002) have also shown efficacy in the prevention of substance use and unsafe sexual behavior among adolescents. In a recent review of the literature, Szapocznik and colleagues (2007) found that only four interventions have been shown to be efficacious in preventing illicit drug use in Hispanic adolescents. The criteria used to select studies in the Szapocznik et al. review were: $(a)$ randomized controlled trials, $(b)$ adolescents ages 12-17 and $(c)$ the use of a primarily Hispanic sample (i.e., $70 \%$ or greater) or reporting of separate results for Hispanics. Using the same criteria, only two interventions have been shown to be efficacious in preventing unsafe sexual behavior in Hispanic adolescents (Prado et al., 2007; Villaruel, Jemmott, \& Jemmott, 2006) and only one intervention (i.e., Familias Unidas) has been found to be efficacious in preventing both substance use and unsafe sexual behavior among Hispanic adolescents (Prado et al., 2007).

Familias Unidas (Pantin et al., 2003; Pantin et al., 2009; Prado et al., 2006; Prado et al., 2007) is a Hispanic-specific, family-based preventive intervention designed to reduce risks and increase protection for substance use and unprotected sexual behavior in Hispanic adolescents. As stated earlier, Familias Unidas is guided by ecodevelopmental theory (Szapocznik \& Coatsworth, 1999) and influenced by culturally specific models developed for Hispanic populations in the United States (Szapocznik \& Kurtines, 1993; Szapocznik \& Williams, 2000). Consistent with ecodevelopmental theory, Familias Unidas aims to prevent substance use and unprotected sexual behavior by increasing positive parenting, family support of the adolescent, parental involvement, as well as by improving general parent-adolescent communication and parent-adolescent communication specific to substance use, unsafe sexual behavior and HIV (Pantin, et al, 2004). As can be seen from Figure 1, the family microsystemic processes are influenced by exosystemic (e.g., parent's support network) and mesosystemic processes (e.g., parent-school and parent-peer relationships). The exosystemic processes are influenced by marcosystemic processes (e.g., cultural influences).

The Familias Unidas intervention was developed through a community-based participatory research model. For example, in preparation for Familias
Unidas, community representatives identified sexual risk behavior and substance use as particular causes for concern amongst local parents (Coatsworth, Pantin, \& Szapocznik, 2002) and consequently the intervention was developed to specifically target these outcomes. Additionally, during focus groups for the development of the Familias Unidas intervention, parents highlighted the role of acculturation to the American culture as an important reason why their youth were engaging in problem behaviors. Consequently, Familias Unidas was developed to address very well defined cultural risk and protective processes such as acculturation stressors.

Familias Unidas is delivered through multi-parent groups that place parents in the change agent role and through family visits. Parent groups are the main activity of the intervention, which bring parents together for the purposes of establishing parental investment, increasing parental support and providing a context for parent participation in a conjoint skills learning process. The most important process used to achieve these goals is "participatory learning", based on the problem posing approach pioneered by Paolo Freire for use with marginalized populations. In participatory learning, parents learn through dialogue rather than instruction. Group activities such as role plays and other forms of behavioral rehearsal aid in skill acquisition. Throughout the group sessions, parents build perceived responsibility and control (i.e. self-efficacy).

Family visits provide the first contact between the facilitator and the families, but most importantly, their purpose is to provide the facilitator with an opportunity to restructure family, peer and school risk processes. Family visits also provide opportunities for the facilitator to maintain family motivation, practice and implement the skills that the parent learned within the group sessions. Family visits create an opportunity for parents to transfer the competencies learned in the group sessions to their adolescent, foster more nurturing and supportive relationships and increase parentchild communication, all in the context of family.

Working with each family allows the facilitator to involve other family members in the intervention, thereby strengthening the entire family. The facilitator may also explore perceived barriers to intervention attendance and work with the family to resolve key issues opening the family to the Familias Unidas intervention. Our high engagement rates (Prado et al., 2006) of over $90 \%$ in the intervention sessions can be attributed to the content and to the process of the first family visit, which include exploring and addressing the family's problem areas, joining with the family and describing the Familias Unidas intervention.

Family visits also allow the family and facilitator to synthesize what is obtained from the parent group sessions and apply it specifically to those issues and problems presently occurring in the family. Family visits are focused specifically on the processes occurring 
within a specific family and how these interactions set the stage for being able to apply the skills learned in the group sessions to their everyday life.

\section{Familias Unidas: Research Findings from three Efficacy Studies}

Familias Unidas has been evaluated and found to be efficacious in preventing and reducing substance use (including alcohol use, cigarette use and illicit drug use) and unprotected sexual behavior in three randomized clinical trials (Pantin et al., 2003; Pantin et al., 2009; Prado et al., 2007). According to the Institute of Medicine's (O'Connell et al., 2009) most recent report on Preventing Mental Health, Emotional and Behavioral Disorders among Young People, Familias Unidas is only one of two interventions that have been found to be efficacious in preventing HIV risk behaviors in multiple trials. It is the only intervention that was specifically developed for Hispanic youth. This section summarizes the results of the three efficacy studies.

First Efficacy Study of Familias Unidas. In this first efficacy study of Familias Unidas, Pantin and colleagues (2003) evaluated the efficacy of Familias Unidas, relative to a prevention as usual control condition, in improving family functioning and in reducing behavior problems, an antecedent for substance use, unsafe sexual behavior and related health outcomes such as HIV (Prado et al., 2006). Participants in the study were 102 boys and 65 girls (mean age $=12.4, S D$ $=.80$ ) and their primary caregivers. The median annual household income was between $\$ 15,000$ and $\$ 20,000$. Forty nine percent of adolescents were born in the United States. Immigrant adolescents were born in Cuba (39\%), Central America (29\%), South America (17\%), Puerto Rico (5\%) and other Hispanic countries $(10 \%)$. Of foreign born adolescents, more than a quarter $(26.3 \%)$ of the adolescents had been residing in the United States for less than 5 years. Parents of U.S. born adolescents were born primarily in Cuba (33\%), Nicaragua $(29 \%)$ and Honduras $(11 \%)$.

This study used a 2 (Condition) $\times 4$ (Time) randomized controlled design. Participants were assessed at baseline, randomized and reassessed at 3, 6, 9 and 12 months post baseline. The study used an intent-to-treat design, such that participants continued to be assessed at each timepoint, whether or not they had completed the intervention. Familias Unidas was found to significantly increase family functioning compared to the prevention as usual control condition, $F(4,577)=2.68$, $p<.04$ and to reduce adolescent behavior problems, $F(3,424)=4.25, p<.006$. The results also indicated that changes in family functioning were related to subsequent changes in adolescent behavior problems. The study provided evidence that a Hispanic specific, parent-centered preventive intervention based on ecodevelopmental principles could increase family processes associated with protection against substance use and related negative health outcomes. A limitation of the study, however, was that there was no long-term follow up to assess the impact of the intervention on adolescent substance use. The base rates of substance use were too low to uncover intervention effects at the one year post intervention follow-up when adolescents were 13.4 years of age, on average. Additionally, data on adolescent sexual behavior were not collected.

Second Efficacy Study of Familias Unidas. In this second study of Familias Unidas, Prado and colleagues (2007) evaluated the efficacy of Familias Unidas in preventing adolescent alcohol, cigarette and illicit drug use as well as unsafe sexual behavior, relative to an HIV preventive intervention and a cardiovascular preventive intervention. Participants in the study were 128 boys and 138 girls (mean age $=13.4, S D=.68$ ) and their primary caregivers. Only $18.6 \%$ of the families reported household incomes greater than $\$ 30,000$ per year. Forty percent of adolescents were born in the United States. Immigrant adolescents $(n=159)$ were born in Cuba (40\%), Nicaragua (25\%), Honduras (9\%), Colombia (4\%) and other Hispanic countries (22\%). Of foreign born adolescents, exactly half had been living in the United States for less than three years, whereas the other rest had either been living in the United States between 3-10 years $(n=54,34 \%)$ or more than 10 years $(n=25,16 \%)$. Parents of U.S. born adolescents were born primarily in Nicaragua (33\%), Cuba (20\%) and Honduras (12\%).

This study used a 3 (Condition) $\times 5$ (Time) randomized controlled design. Participants were assessed at baseline, randomized and reassessed at 6, 12, 24 and 36 months post baseline. Like the first efficacy study, this study also used an intent-to-treat design. This second efficacy study evaluated the efficacy of Familias Unidas plus Parent Adolescent Training about HIV, a parent-based HIV preventive intervention relative to (a) PATH plus English for Speakers of Other Languages (ESOL) and (b) ESOL plus HEART, a cardiovascular health promotion intervention. The ESOL + PATH condition focused specifically on increasing parent-adolescent communication about sex and HIV risks (Krauss, Godfrey, Yee et al., 2000). However, unlike Familias Unidas + PATH, it did not target positive parenting or general communication skills, which may be a necessary prerequisite to initiating parentadolescent discussions about sexuality and HIV (cf. Rodgers, 1999). Similarly, the ESOL + HEART condition focused specifically on increasing parent-adolescent communication regarding risk factors for cardiovascular disease (including cigarette use).

The results of the study showed that (a) Familias Unidas + PATH was efficacious in preventing and reducing cigarette use relative to both control condi- 
tions $(z=3.25, p<.002, d=.54, z=2.66, p<.008$, $d=.80$ for ESOL + PATH and ESOL + HEART, respectively); (b) Familias Unidas + PATH was efficacious, relative to ESOL + HEART, in reducing illicit drug use $(z=2.02, p<.05, d=.58)$ and (c) Familias Unidas + PATH was efficacious, relative to ESOL + PATH, in reducing unsafe sexual behavior (19.2\% vs. $\left.44.4 \%, \chi^{2}(1)=3.87, p<.05, w=.27\right)$. Our largest effect size was with cigarette use. As reported in the article reporting the study's primary findings, the proportion of adolescents reporting current cigarette use in Familias Unidas + PATH decreased from 3.3\% to $1.4 \%$, whereas it increased in both ESOL + PATH (from $1.2 \%$ to $10 \%$ ) and ESOL + HEART $+\mathrm{H}$ (from $3.3 \%$ to $14.3 \%)$.

What is most interesting about these findings (other than the fact that the findings support the efficacy of Familias Unidas + PATH) is that the intervention condition that specifically encouraged parents to communicate with their youth about risk factors for cardiovascular disease (including cigarette use) was the intervention condition that fared the worst with respect to this outcome. In light of these findings, our research team compared the trajectories of cigarette use by adolescent subgroups. Subgroups were empirically derived based on adolescent's report of parental involvement, positive parenting, family cohesion, parent-adolescent communication and family support (Prado, Schwartz, Maldonado-Molina et al., 2009). Although four subgroups were empirically derived in the Prado et al. (2009) study (two with Low Family Risk, a third with low to moderate family risk and a fourth with high family risk), for purposes of this study we combined both low family risk subgroups and the low to moderate family risk subgroup into one. Hence, we compared the trajectories of current cigarette use by condition across two risk subgroups: low to moder- ate family risk and high family risk. As can be seen from Figure 2, approximately $33 \%$ of adolescents who reported high family risk and were randomized to ESOL + HEART reported current cigarette use by the 36-month post baseline assessment. On the other hand, 9.4\% of adolescents who reported low family risk and were randomized to ESOL + HEART reported current cigarette use by the 36-month post baseline assessment (Figure 3). Thus, it appears that the intervention condition that specifically encouraged parents to communicate with their youth regarding risks for cardiovascular disease (including cigarette use) was iatrogenic for adolescents who reported poor communication with their parents, low parental involvement and support, lack of family cohesion. It is important, however, to note that this study did not have a no contact control condition and hence it is impossible to determine with certainty whether the cardiovascular preventive intervention was indeed iatrogenic (Szapocznik \& Prado, 2007). Nonetheless, these findings suggest that targeting specific health behaviors such as cigarette use may be counter-productive, particularly among vulnerable youth who have high family risk factors such as poor parent-adolescent communication.

In addition to demonstrating an effect on current cigarette use, drug use and unprotected sexual behavior at last sexual intercourse, Familias Unidas + PATH was also efficacious in preventing cigarette use initiation $(10.8 \%$ in Familias Unidas + PATH, 24.3\% in ESOL + PATH and $27.1 \%$ in ESOL + HEART, $\chi^{2}(2)=$ $6.79, p<.04, w=.18$ ) and in preventing the incidence of sexually transmitted diseases $(0 \%$ in Familias Unidas + PATH, $1.2 \%$ in ESOL + PATH and $5.9 \%$ in ESOL + HEART, Fisher's Exact $p$-value $=.05)$. A limitation of the study was that the data gathered on sexually transmitted diseases were self-report.

Third Efficacy Study of Familias Unidas. In this

Figure 2. Percent reporting Past 90 days Cigarette Use by condition for High Family Risk

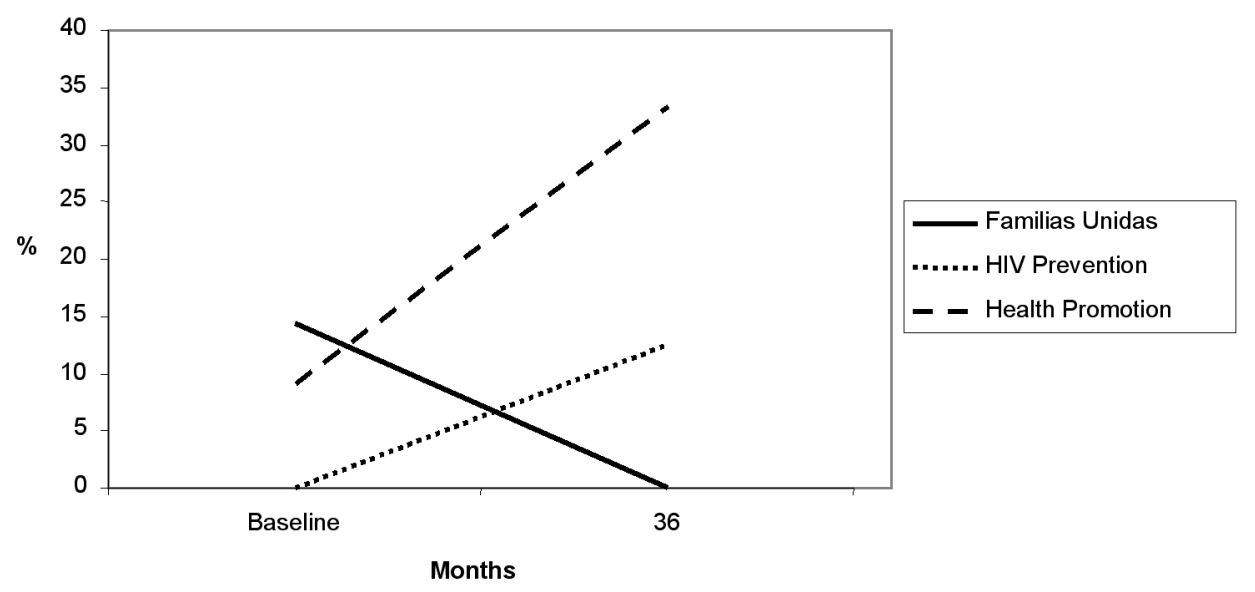

High Family Risk 
Figure 3. Percent reporting Past 90 days Cigarette Use by condition for Low to Moderate Family Risk

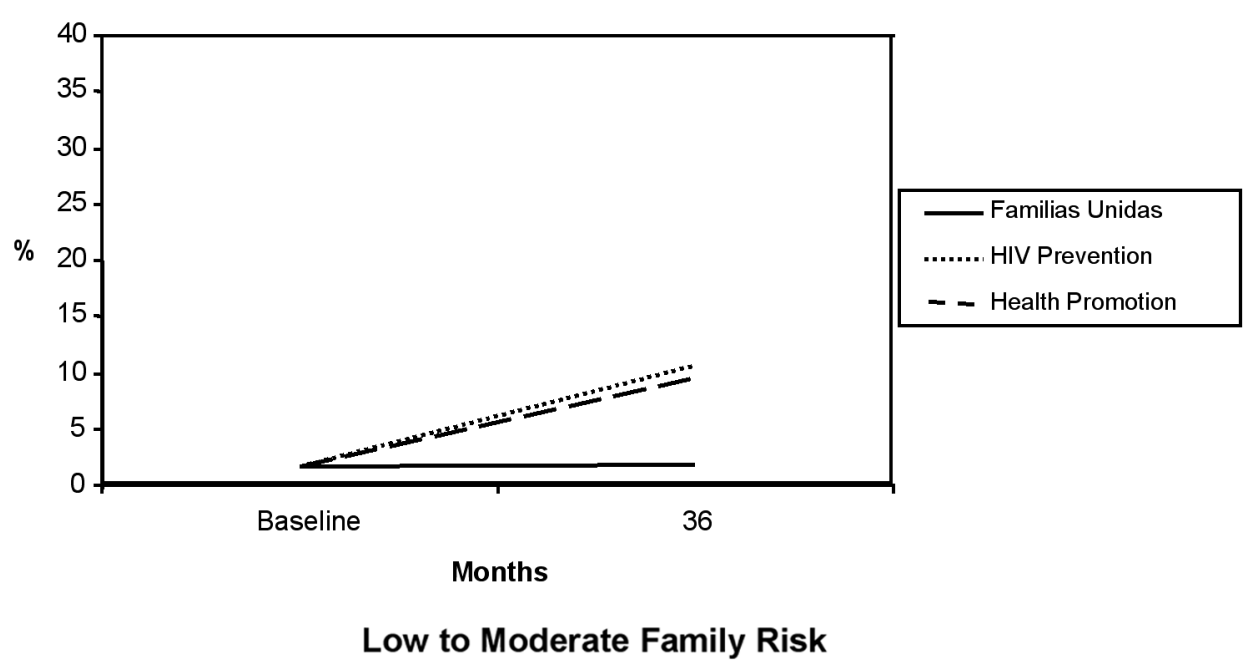

third study of Familias Unidas, Pantin and colleagues (2009) evaluated the efficacy of Familias Unidas in preventing adolescent substance use as well as unsafe sexual behavior relative to a prevention as usual control condition. Unlike the first two efficacy studies, this third efficacy study consisted of an indicated sample of Hispanic youth who were selected because they had clinical levels of behavior problems.

Participants in the present study were 136 boys and 77 girls (mean age $=14.3, S D=0.7$ ) and their primary caregivers. Consistent with the demographic characteristics of our other two efficacy studies, only $13.1 \%$ of the families reported household incomes greater than $\$ 30,000$ per year and over half $(56.1 \%)$ of the adolescents were born in the United States. Of foreign born adolescents, 36.6\% $(n=34)$ had been living in the United States for less than three years, whereas the others had either been living in the United States between 3-10 years $(n=42,45.2 \%)$ or more than 10 years $(n=17,18.3 \%)$. At baseline, the majority (74.2\%) of the participating adolescents self-reported having at least one major psychiatric disorder using the Diagnostic Interview Schedule for Children predictive scales (DISC-DPS: Lucas et al., 2001). Of the $74.2 \%$ of adolescents who self-reported one disorder, $78.1 \%$ reported at least one other disorder. The most common self-reported disorder was Attention deficit hyperactivity disorder (33.0\%), followed by Panic disorder (29.2\%) and Obsessive-Compulsive disorder $(29.2 \%)$.

This third study used a 2 (Condition) $\times 4$ (Time) randomized controlled design. Participants were assessed at baseline, randomized and reassessed at 6 , 18 and 30 months post baseline. This third study also used an intent-to-treat design. As with the first two efficacy studies, Familias Unidas was found to improve family functioning compared to the control condition, $F(1,211)=17.5, p<.001$. The results also showed that Familias Unidas was efficacious, relative to prevention as usual in reducing substance use ( $b=0.53, z=2.42, p<.02, d=0.25)$ as well as in reducing the frequency of unprotected sexual behavior ( $b=-0.32, z=-2.3, p<.03, d=0.25)$. The analyses showed that family functioning mediated the effects of condition on substance use. Finally, the results of this third efficacy study, showed that Familias Unidas was efficacious in preventing the incidence of adolescent externalizing problem behaviors.

In summary, Familias Unidas, a Hispanic-specific family-based intervention has been found to be efficacious in reducing substance use and HIV risk behaviors in Hispanic youth. To have a broader impact, however, Familias Unidas should be evaluated in a "real world" setting so that its effectiveness can be determined and so that consequently the intervention can be translated to community public health practice. The next section describes a National Institutes of Health funded Stage III effectiveness study of Familias Unidas that will test the effectiveness of Familias Unidas throughout Miami Dade County.

\section{Moving Familias Unidas from Research to Practice}

Now that the efficacy of Familias Unidas has been established, our team is evaluating the effectiveness of the intervention in preventing substance use and unprotected sexual behavior in a population based, representative sample of Hispanic youth in Miami-Dade County. In this study, we take the view that an effectiveness trial should test a defined intervention (in this case Familias Unidas) that is delivered by intervention agents within community settings in a manner that could ultimately be used for large scale implementation and dissemination. We also take the view that effectiveness trials should be conducted with rigorous randomized trial designs, 
trained clinicians and intervention manuals (Brown, Wang, Kellam et al., 2008; Flay, 1986).

This effectiveness study uses a 2 (Condition) $\times 4$ (Time) randomized controlled design. Participants will be assessed at baseline, randomized and reassessed at 6,18 and 30 months post baseline. A total of 31 youth and their primary caregivers from 24 schools will comprise the study sample. Unlike our efficacy study, where facilitators were highly skilled clinicians working for the research team, in this effectiveness study facilitators will consist of trust specialists and social workers at each of the participating middle schools. Miami-Dade Public Schools are partnering with us under a subcontract to this effectiveness study and the Director of Mental Health and Crisis Management Services, Miami-Dade County Public Schools is a co-investigator on the study and will help supervise the Trust Counselors and Social Workers who will facilitate the intervention. Using Trust Counselors and Social Workers to deliver the intervention will test whether the intervention will be effective when delivered by staff within the public school system as would occur during large scale implementation and dissemination and will maximize the chances that this intervention, if effective, will be broadly disseminated and sustained in community practice. Ultimately, moving interventions, such as Familias Unidas, from efficacy to effectiveness to implementation to broad dissemination is essential to reducing the health disparities that exist between Hispanics and other segments of the population.

\section{Conclusions}

Preventing/reducing substance use and HIV among Hispanic youth is essential to eliminating the health disparities that exist between Hispanics and other segments of the population. Familias Unidas is a behavioral intervention with demonstrated efficacy in preventing both substance use and unprotected sexual behavior among Hispanic youth. The intervention was developed through a community-based participatory research model, has been found efficacious in three randomized trials and is now being translated to community practice. Moving interventions such as Familias Unidas from development and feasibility studies, to efficacy, to implementation, to community based practice and broad dissemination is important if we are to reduce health disparities and make a substantial impact on the health of the Hispanic population.

\section{Acknowledgments}

This article was supported by NIDA grants \# 1R01DA025192-01A1 and 1R01DA025894-01 as well as NIDA and NIAAA grant \#3R01DA025192-
01A1S1 awarded to Guillermo Prado. We would like to thank our research team (including our facilitators, assessors, and data analyst), Miami-Dade County Public Schools, and the families that have contributed to this program of research over the years.

\section{References}

Bailey, S. L., Pollock, N. K., Martin, C. S., \& Lynch, K. G. (1999). Risky sexual behaviors among adolescents with alcohol use disorders. The Journal of Adolescent Health, 25, 179-181.

Barnes, G. M., Farrell, M. P., \& Banerjee, S. (1994). Family influences on alcohol abuse and other problem behaviors among Black and White adolescents in a general population sample. Journal of Research on Adolescence, 4, 183201.

Bogenschneider, K., Wu, M. Y., Raffaelli, M., \& Tsay, J. C. (1998). Parent influences on adolescent peer orientation and substance use: The interface of parenting practices and values. Child Development, 69, 1672-1688.

Boyer, C. B., Tschann, J. M., \& Shafer, M. A. (1999). Predictors of risk for sexually transmitted diseases in ninth grade urban high school students. Journal of Adolescent Research, 14, 448-465.

Bronfenbrenner, U. (1979). The ecology of human development: Experiments by nature and design. Cambridge, MA: Cambridge University Press.

Bronfenbrenner, U. (1986). Ecology of the family as a context for human development. The American Psychologist, 32, 513-531.

Brown, C. H., Wang, W., Kellman, S. G., Muthen, B. O., Petras, H., Toyinbo, P. et al. (2008). Methods for testing theory and evaluating impact in randomized field trials: Intent-to-treat analyses for integrating the perspectives of person, place, and time. Drug and Alcohol Dependence, 95S, S74-S104.

Brown, C. H., Wang, W., Kellam, S. G., Muthen, B. O., Petras, H., Toyinbo, P., et al. (in press). Methods for testing theory and evaluating impace in randomized field trials: intent-to-treat analysis for integrating the perspectives of person, place and time. Journal of Drug and Alcohol Dependence.

Bry, B. H., McKeon, P., \& Pandina, R. J. (1982). Extent of drug use as a function of number of risk factors. Journal of Abnormal Psychology, 91, 273-279.

Centers for Disease Control and Prevention (2010). HIV Surveillance Report 2008; vol. 20. http://www.cdc.gov/ hiv/topics/surveillance/resources/reports/. Published June 2010. Accessed Janaury 13, 2011.

Coatsworth, J. D., Pantin, H., \& Szapocznik, J. (2002). Familias Unidas: A family-centered ecodevelopmental intervention to reduce risk for problem behavior among Hispanic adolescents. Clinical Child and Family Psychology Review, 5, 113-132.

Dishion, T. J., Capaldi, D. M., \& Yoerger, K. (1999). Middle childhood antecedents to progressions in male ado- 
lescent substance use: An ecological analysis of risk and protection. Journal of Adolescent Research, 14, 175-205.

Dishion, T. J., Kavanagh, K., Schneiger, A., Nelson, S., \& Kaufman, N. K. (2002). Preventing early adolescent substance use: A family-centered strategy for the public middle school. Prevention Science, 3, 191-201.

Eaton, D. K., Kann, L., Kinchen, S., Ross, J., Hawkins, J., Harris, W. A., ... Wechsler, H. (2006). Youth Risk Behavior Surveillance-United States 2005. Morbidity and Mortality Weekly Report. Surveillance Summary, 55, $1-108$.

Flay, B. R. (1986). Efficacy and effectiveness trials (and other phases of research) in the development of health promotion programs. Preventive Medicine, 15, 451-474.

Ford, K. \& Norris, A. E. (1993). Knowledge of AIDS transmission, risk behavior and perceptions of risk among urban, low-income, African-American and Hispanic youth. American Journal of Preventive Medicine, 9, 297306.

Friedman, L. M., Furberg, C. D. \& DeMets, D. L. (1998). Fundamentals of clinical trials 3rd Edition. New York: Springer-Verlag.

Garbarino, J. \& Abramowitz, R. H. (1992). The ecology of human development. Children and Families in the Social Environment, 2, 11-33.

Gil, A. G., Wagner, E. F., \& Tubman, J. G. (2004). Culturally sensitive substance abuse intervention for Hispanic and African American adolescents: Empirical examples from the Alcohol Treatment Targeting Adolescents in Need (ATTAIN) Project. Addiction, 99, 140-150.

Greene, J. P. \& Forster, G. (2003). Public high school graduation and college readiness rates in the United States. Manhattan Institute, September 2003.

Guo, J., Chung, I. J., Hill, K .G., Hawkins, J. D., Catalano, R. F., \& Abbott, R. D. (2002). Developmental relationships between adolescent substance use and risky sexual behavior in young adulthood. The Journal of Adolescent Health, 31, 354-362.

Hawkins, J. D., Catalano, R. F., \& Miller, J. Y. (1992). Risk and protective factors for alcohol and other drug problems in adolescence and early adulthood: Implications for substance abuse prevention. Psychological Bulletin, 112, 64-105.

Hovell, M., Sipan, C., Blumberg, E., Atkins, C., Hofstetter, C. R., \& Kreitner S. (1994). Family influences on Latino and Anglo adolescents' sexual behavior. Journal of Marriage and the Family, 56, 973-986.

Ialongo, N. S., Werthamer, L., Kellam, S. G., Brown, C. H., Wang, S., \& Lin Y. (1999). Proximal impact of two firstgrade preventive interventions on the early risk behaviors for later substance abuse, depression and antisocial behavior. American Journal of Community Psychology, 27, 599-641.

Johnston, L. D., O’Malley, P. M., Bachman, J. G., \& Schulenberg, J. E. (2009). Monitoring the future national results on adolescent drug use: Overview of key findings, 2008 (NIH Publication No. 08-6418) (pp. 70). Bethesda, MD: National Institute on Drug Abuse.
Kotchick, B. A., Shaffer, A., Forehand, R., \& Miller, K. S. (2001). Adolescent sexual risk behavior: A multi-system perspective. Clinical Psychology Review, 21, 493-519.

Krauss, B. J., Godfrey, C., Yee, D., Goldsamt, L., Tiffany, J., Almeyda, L., et al. (2000). Saving our children from a silent epidemic: The PATH program for parents and preadolescents. In W. Pequegnat \& J. Szapocznik (Eds.), Working with families in the era of HIVIAIDS (pp. 89112). Thousand Oaks, CA: Sage.

Kulis, S., Marsiglia, F. F., Elek, E., Dustman, P., Wagstaff, D. A., \& Hecht, M. L. (2005). Mexican/Mexican American adolescents and Keepin' it REAL: An evidence-based substance abuse prevention program. Children \& Schools, 27, 133-145.

Kumpfer, K. L., Molgaard, V., \& Spoth, R. (1996). The Strengthening Families Program for the prevention of delinquency and drug use. In R. D Peters, \& R. J. McMahon (Eds). Preventing childhood problems, substance abuse and delinquency (pp. 241-267). Thousand Oaks, CA: Sage.

Leon, A. M., \& Dziegielewski, S. F. (2000). Engaging Hispanic immigrant mothers: Revisiting the time-limited psycho-educational group model. Crisis Intervention, 6, 13-27.

Luster, T. \& Small, S. A. (1994). Factors associated with sexual risk-taking behaviors among adolescents. Journal of Marriage and the Family, 56, 622-632.

Marotta, S. A. \& Garcia, J. G. (2003). Latinos in the United States in 2000. Hispanic Journal of Behavioral Sciences, $25,13-34$

Martinez, C. R. (2006). Effects of differential family acculturation on Latino adolescent substance use. Family Relation, 55, 306-317.

Miller, K. S., Levin, M. L., Whitaker, D. J., \& Xu, X. (1998). Patterns of condom use among adolescents: the impact of mother-adolescent communication. American Journal Of Public Health, 88, 1542-1544.

Mokdad, A. H., Marks, J. S., Stroup, D. F., \& Gerberding, J. L. (2004). Actual causes of death in the United States, 2000. The Journal of the American Medical Association, 291, 1238-1245.

O'Connell, M. E., Boat, T., \& Warner, K. E. (Eds). (2009). Preventing mental, emotional and behavioral disorders among young people. Progress and possibilities. Committee on Prevention of Mental Disorders and Substance Abuse among Children, Youth and Young Adults: Research Advances and Promising Interventions. Washington, DC: The National Academies Press.

Pabon, E. (1998). Hispanic adolescent delinquency and the family: A discussion of sociocultural influences. Adolescence, 33, 941-955.

Pantin, H., Coatsworth, J. D., Feaster, D. J., Newman, F. L., Briones, E., Prado, G., ... Szapocznik, J., (2003). Familias Unidas: The efficacy of an intervention to promote parental investment in Hispanic immigrant families. Prevention Science, 4, 189-201.

Pantin, H., Prado, G., Huang, S., López, B., Tapia, M. Sabillon, E., ... Branchini, J. (2009). A randomized controlled 
trial of Familias Unidas for Hispanic beahavior-problem adolescents. Psychosomatic Medicine, 71, 987-995.

Pantin, H., Schwartz, S. J., Sullivan, S., Prado, G., \& Szapocznik, J. (2004). Ecodevelopmental HIV prevention programs for Hispanic adolescents. The American Journal of Orthopsychiatry, 74, 545-558.

Pentz, M. A. (1995). Prevention research in multiethnic communities: Developing community support and collaboration and adapting research methods. In G. J. Botvin, S. Schink, M. A. Orlandi (Eds), Drug abuse prevention in multi-ethnic youth (pp. 193-214). Thousand Oaks: Sage.

Pentz, M. A., Dwyer, J. H., MacKinnon, D. P., Flay, B. R., Hansen, W. B., Wang, E. Y., Johnson \& C. A. (1989). A multicommunity trial for primary prevention of adolescent drug abuse. Effects on drug use prevalence. Journal of the American Medical Association, 261, 3259-3266.

Perkins, D. F. \& Luster, T. (1999). The relationship between sexual abuse and purging: Findings from communitywide surveys of female adolescents. Child Abuse \& Neglect, 23, 371-382.

Prado, G. Huang, S., Maldonado-Molina, M., Bandiera, F., Schwartz, S. J., de la Vega, P., ... Pantin, H. (2010). An empirical test of ecodevelopmental theory in predicting HIV risk behaviors among Hispanic youth. Health Education and Behavior, 37, 97-114.

Prado, G., Pantin, H., Briones, E., Schwartz, S. J., Feaster, D., Huang, S., ... Szapocznik, J. (2007). A randomized controlled trial of a parent-centered intervention in preventing substance use and HIV risk behaviors in Hispanic adolescents. Journal of Consulting and Clinical Psychology, 75, 914-926.

Prado, G. J., Schwartz, S. J., Maldonado-Molina, M., Huang, S., Pantin, H. M., Lopez, B., \& Szapocznik, J. (2009). Ecodevelopmental $\mathrm{x}$ intrapersonal risk: Substance use and sexual behavior in Hispanic adolescents. Health Education \& Behavior, 36, 45-61.

Prado, G., Schwartz, S. J., Pattatucci-Aragon, A., Clatts, M., Pantin, H., Fernandez, M. I., ... Szapocznik, J. (2006). The prevention of HIV transmission in Hispanic adolescents. Drug and Alcohol Dependence, 84, S43-53.

Ramirez, R. R., \& de la Cruz, G. P. (2003). The Hispanic population in the United States: March 2002: Population characteristics. Current Population Reports (pp. 20-545). Washington, D.C: US Census Bureau.

Simons, R. L., Lorenz, F. O., Conger, R. D., \& Wu, C. I. (1992). Support from spouse as mediator and moderator of the disruptive influence of economic strain on parenting. Child Development, 63, 1282-1301.

Storr, C. L., Ialongo, N. S., Kellam, S. G., \& Anthony, J. C. (2002). A randomized controlled trial of two primary school intervention strategies to prevent early onset tobacco smoking. Drug and Alcohol Dependence, 66, 5160.

Swick, K. J. \& Broadway, F. (1997). Parental efficacy and successful parent involvement. Journal of Instructional Psychology, 24, 69-75.

Szapocznik, J. \& Coatsworth, J. D. (1999). An ecodevelopmental framework for organizing the influences on drug abuse: A developmental model of risk and protection. In M. D. Glantz, \& C. R. Hartel (Eds.), Drug abuse: Origins \& interventions (pp. 331-66). Washington, DC: American Psychological Association.

Szapocznik, J. \& Kurtines, W. M. (1993). Family psychology and cultural diversity: Opportunities for theory, research and application. American Psychologist, 48, 400-407.

Szapocznik, J. \& Prado, G. (2007). Negative effects on family functioning from psychosocial treatments: A recommendation for expanded safety monitoring. Journal of Family Psychology, 21, 468-478.

Szapocznik, J., Prado, G., Burlew, A. K., Williams, R. A., \& Santisteban, D. A. (2007). Drug abuse in African American and Hispanic adolescents: Culture, development and behavior. Annual Review of Clinical Psychology, 3, 77-105.

Szapocznik, J., Scopetta, M. A., \& King, O. E. (1978). Theory and practice in matching treatment to the special characteristics and problems of Cuban immigrants. Journal of Community Psychology, 6, 112-122.

Szapocznik, J. \& Williams, R. A. (2000). Brief Strategic Family Therapy: Twenty-five years of interplay among theory, research and practice in adolescent behavior problems and drug abuse. Clinical Child and Family Psychology Review, 3, 117-134.

Tobler, N. S., Roona, M. A., Ochshorn, P., Marshall, D. G., Streke, A.V., \& Stackpole, K. M. (2000). School-based adulescent drug prevention programs: 1998 meta-analysis. Journal of Primary Prevention, 20, 275-335.

U. S. Census Bureau. (2008). U. S. Hispanic population surpasses 45 million now 15 percent of total. Retrieved March 9, 2009, from http://www.census. gov/PressRelease/www/releases/archives/population/011910. html

Villaruel, A. M., Jemmott, J. B., \& Jemmott, L. S. (2006). A randomized controlled trial testing an HIV prevention intervention for Latino youth. Archives of Pediatrics and Adolescent Medicine, 160, 772-777.

Whitbeck, L. E., Conger, R. D., \& Kao, M. Y. (1993). The influence of parental support, depressed affect and peers on the sexual behaviors of adolescent girls, Journal of Family Issues, 14, 261-278.

Manuscript received: 28/06/2010 Review received: 22/07/2010 Accepted: 27/07/2010 